\title{
Plasma Exchange for Hemolytic Crisis and Acute Liver Failure in Wilson Disease: Authors' Reply
}

\author{
Nishant Verma $\cdot$ Rakesh Lodha
}

Received: 1 July 2013 / Accepted: 11 July 2013 / Published online: 31 August 2013

(C) Dr. K C Chaudhuri Foundation 2013

To the Editor: We thank Dr Kumar for taking interest in our article [1]. We agree with the author that use of modalities like plasmapheresis should be considered in Wilson's disease- Acute liver failure (WD-ALF); as seen in our case and in other cases mentioned by the author, plasmapheresis can either provide a bridge to liver transplant or rarely prevent the transplant. The commonly used prognostic scoring system- the revised Wilson's Prognostic Index was devised after retrospective review of 74 Wilsons disease (WD) children at the King's College Hospital, London between 1967 and 2000 [2]. The revised score was tested prospectively in 14 WD children between 2001 and 2003 [2]. The validity of this score in the present era with availability of newer hepatic assist systems remains to be established in a larger number of patients. Over-reliance on the prognostic scoring systems may result in unnecessary transplants and misallocation of a rare resource [3].

To conclude, if a child presents in WD-ALF, medical treatment should be started. The medical treatment may include modalities like plasmapheresis/hemofiltration/MARS. Simultaneously the liver transplant services should also be alerted regarding the possible need for a transplant. However, the decision regarding when to proceed for the transplant is a complex one and will vary from case to case.

\section{References}

1. Verma N, Pai G, Hari P, Lodha R. Plasma exchange for hemolytic crisis and acute liver failure in Wilson Disease. Indian J Pediatr. 2013 Mar 14. [Epub ahead of print]; doi:10.1007/s12098-013-0979-x.

2. Dhawan A, Taylor RM, Cheeseman P, De Silva P, Katsiyiannakis L, Mieli-Vergani G. Wilson's disease in children: 37-year experience and revised King's score for liver transplantation. Liver Transpl. 2005; 11:441-8.

3. Fischer RT, Soltys KA, Squires RH Jr, Jaffe R, Mazarieqos GV, Shneider BL. Prognostic scoring indices in Wilson disease: A case series and cautionary tale. J Pediatr Gastroenterol Nutr. 2011;52: 466-9.
N. Verma $\cdot$ R. Lodha $(\bowtie)$

Department of Pediatrics, All India Institute of Medical Sciences, Ansari Nagar, New Delhi 110029, India

e-mail: rakesh_lodha@hotmail.com 